\title{
Inovação, renovação e ambidestria: chaves para a aprendizagem do jornalismo no século XXI
}

\author{
CARlos EduARDo CoRTÉS - ccort4@gmail.com \\ Free Press Unlimited - Holanda \\ Jornalista, coordenador de Programas/Liaison para a América Latina.
}

\begin{abstract}
Resumo
Este artigo aborda as mudanças que ocorrem no mundo da mídia e do jornalismo devido ao novo modelo de desenvolvimento informacional que se configura com as novas tecnologias digitais de comunicação e informação. Nesse contexto, novas formas de interação, de controles sociais e mudanças nos jogos econômicos resultam em um cenário de crise para as organizações midiáticas; a convergência digital, transmidiática, exige, cada vez mais, fluidez informacional dos indivíduos e grupos; e o jornalismo tradicional e profissional é colocado em questão pelo transbordamento informacional nas redes sociais. Diante disso, o artigo discute a importância das instituições que formam jornalistas e a necessidade de se alargar os métodos de ensino e aprendizagem, no sentido de uma mudança hiper-exponencial.
\end{abstract}

\section{Palavras-chave}

Ensino de Jornalismo. Convergência. Inovação.

\begin{abstract}
The new model of informational development, based on new digital information and communication digital has caused profound and permanent changes in the world of media and journalism: the new forms of interaction, of social controls and changes in economic games result in a crisis scenario to for media organizations; the current transmedia digital convergence, requires increasingly informational fluency of both individuals and groups; the traditional and professional journalism is questioned also by informational overflow in social networks. In this context, the institutions which form journalists acquire fundamental importance. However, the methods of teaching and learning need to be enhanced, incorporating new ICTs and all the resources and tools that the Web offers. It requires, therefore, a hyper-exponential change, in the sense of developing an innovative journalism, allied and favorable to citizen media, to better answer its social function.
\end{abstract}

\section{Keywords}

School of Journalism. Convergence. Innovation. 


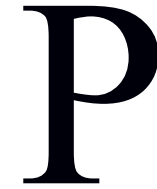

oderíamos fazer uma "moção de encerramento do debate" perante o reconhecimento de dois fatos: 1) a mudança global gerada pela passagem de um modo de desenvolvimento industrial a um outro de desenvolvimento informacional, cuja fonte de produtividade é a tecnologia da geração do conhecimento, o processamento da informação e a comunicação de símbolos, e cuja estrutura de relação humana é a sociedade em rede (CASTELLS, 2000; 1997); 2) a profunda e definitiva mudança organizacional e profissional no mundo da mídia e do jornalismo, derivada do chamado desenvolvimento informacional.

As evidências empíricas globais tornam possível admitir que estamos passando dos meios massivos e seu modelo de broadcasting (rádio e teledifusão) para um novo modelo de digicasting, baseado num conjunto de serviços de textos digitais (vídeo, áudio e dados) escorado, por um lado, na digitalização do uso do espectro eletromagnético, e, por outro, no acesso personalizado (webcasting, narrowcasting, podcasting... ) a redes de banda larga, computadores, telefones celulares e novos dispositivos eletrônicos de comunicação e acesso a redes e reprodução multimídiaii: "O que quero, quanto quero, onde quero e quando quero".

A nova mídia digitalizada e convergente deslocou o modelo do jornalismo tradicional baseado na especialização midiática (imprensa, cinema, rádio e TV, cada um em separado). Se no século XX cada meio constituía uma indústria, hoje essas fronteiras tornam-se difusas e produzem uma viscosidade midiática na qual os gêneros e as tecnologias de distribuição aparecem e desaparecem, mas as mídias permanecem como capas dentro de um, cada vez mais, complexo sistema de informação, educação e entretenimento baseado em redes digitais, o qual modifica tanto a produção como o consumo (JENKINS, 2006; CORTÉS, 2009).

Isto é, não estamos fazendo futurologia, mas reconhecendo fatos consumados. No final do século $\mathrm{XX}$, o novo paradigma tecnológico - constituído em torno da microeletrônica, das tecnologias de informação e comunicação digitais, e da biotecnologia - substituiu ou subsumiu o paradigma do industrialismo - organizado em torno da produção e da distribuição de energia -, e hoje afeta, em maior ou menor medida, todas as sociedades do planeta, em diversas manifestações culturais e institucionais.

Além do mais, no modo de desenvolvimento informacional, a estreita conexão entre cultura e forças produtivas, entre espírito e matéria, permitiu o surgimento de 
novas formas de interação, controle e mudança sociais, algumas das quais contribuíram para deteriorar a democracia em nossa região, devido a fatores inter-relacionados, entre os quais gostaria de destacar três em particular:

A Novas expressões de autoritarismo, militarismo, neopopulismo e estadismo, cuja ação debilita o estado de direito a partir da própria institucionalidade dos governos.

A Avanço do narcotráfico, com todas suas ramificações políticas, econômicas, sociais e culturais, fortalecidas por sua inevitável capacidade de corrupção.

A Renúncia de significativos setores cidadãos a defender a democracia e os diretos humanos, para obter as migalhas de uma precária seguridade urbana que faz com que seja mais aceitável a deteriorada cotidianidade da maioria da população.

Em tais condições, promover o debate democrático como função essencial do jornalismo acaba sendo hoje uma tarefa sitiada pela adversidade do contexto. Ao mesmo tempo, também se vê deslocada pelas prioridades de uma difícil sobrevivência das organizações midiáticas, fustigadas por um contexto corporativo implacável que introduz novas regras de jogo, concentra em excesso, força fusões e absorções anticompetitivas, gera perda de autonomia editorial e produz crises encadeadas de sustentabilidade que se manifestam tanto na mídia comercial, como na pública e comunitária ou cidadã.

Qual é o futuro do jornalismo profissional neste panorama?

Em 1981, o jornal El País de Madri entrevistou Gabriel García Márquez (CEBERÍO, 1981) e lhe perguntou, entre outras coisas, que papel corresponde ao escritor na política deste continente (America Latina). A resposta dele foi simples e direta: "O primeiro dever revolucionário do escritor é escrever bem".

Que papel corresponde ao jornalista no novo contexto? Parafraseando García Márquez, poderíamos dizer: fazer bom jornalismo; manter a excelência profissional como norte permanente perante os obstáculos maiúsculos do contexto. E isso só já seria um desafio imenso. Vejamos por quê. 


\section{A realidade transbordada}

A convergência digital transborda a realidade analógica da radiodifusão. Os atuais meios de rádio e TV continuam sendo a rede de tecnologias de informação e comunicação (TICs) mais entendida e importante da América Latina. Porém, ao mesmo tempo, não podemos continuar produzindo nem pensando as mídias sob o ponto de vista do modelo analógico tradicional (CORTÉS, 2010).

Com a digitalização, temos ingressado em uma crescente viscosidade midiática na qual mudam os conteúdos, os gêneros e as tecnologias de distribuição, mas os meios permanecem como capas dentro de um, cada vez mais, complexo sistema de notícias, informação e entretenimento (CORTÉS, 2008; JENKINS, 2006; JENKINS, THORBURN, 2004).

Isto é, não presenciamos a morte de nenhum meio em particular, mas sua reformulação digital e seu consumo convergente em diversas plataformas, nas quais imagem, som e dados convivem de maneira transversal ou transmidiática (GIBS, 2009), incluída a própria narrativa fragmentada (ou distribuída) em diversas mídias, porém, não sendo interdependentes entre si (JENKINS, 2006).

Por isso, os comunicadores analógicos têm perdido a exclusividade: produzir e distribuir notícias, informação e entretenimento já não são mais um negócio distintivo dos difusores da era analógica. As novas TICs têm o potencial de converter qualquer indivíduo com acesso a elas em produtor, editor e distribuidor digital de conteúdos, e não só em consumidor (prosumidor) ${ }^{\text {iii. }}$.

Mas este potencial passa por certas destrezas necessárias. Hoje é preciso gerar produtos e processos comunicacionais conducentes a que tanto os indivíduos quanto os grupos sociais adquiram uma maior fluidez informacional, entendida, basicamente, como a competência para ter uma performance efetiva em um contexto intenso em tecnologia e rico em informação (CORTÉS, 2006; UNIVERSITY OF CENTRAL FLORIDA, 2005).

O conceito é resultado de uma síntese de posições historicamente distanciadas e, por vezes, enfrentadas entre especialistas nas ciências da informação, partidários da chamada "alfabetização informativa" (information literacy), e engenheiros de sistemas de tecnologia da informação (TI), adeptos da "alfabetização computacional" (computer literacy). 
Todo ser humano, pelo fato de viver em comunidade, tem a capacidade de adquirir fluidez linguística com o aprendizado de uma língua materna. Porém, quando nos referimos à fluidez informacional, falamos de como a sociedade está hoje mediada pelas TICs digitais, de maneira que a performance comunicacional de um indivíduo ou de um grupo depende não só de sua fluidez linguística, mas também da sua familiaridade com as chamadas TICs e de sua capacidade cognitiva para buscar, processar e usar informação.

E se reconhecemos o jornalismo como um modo de dizer e fazer a vida social e de a sociedade se dizer a si mesma (PINTO, 1999), veremos que a linguagem é a ferramenta de trabalho do jornalista, e que sua fluidez informacional está duplamente desafiada pela cultura digital.

Se o século XX foi a era do trabalho industrial, da produção e do consumo massivos, uma característica cada vez mais definidora do século XXI é a "participação massiva" ou a "cultura participativa" em rede, que abre alas a novas formas de contrapoder (ou poder de baixo pra cima) (JENKINS, 2007). No entanto, para o jornalismo tradicional, essa mudança significa que ele tem sido posto em xeque pelo transbordamento informacional e comunicacional das chamadas "redes sociais", que têm gerado formas de circulação de informação, e de socialização, impensadas e impensáveis há somente um quinquênio.

À medida que as novas gerações mostram mais credibilidade em seus pares do que nas mídias tradicionais, questionadas pela arremetida da nova mídia social, não profissionalizada nem profissionalizante, tais como blogs, microblogs, vlogs, fóruns online e wikis..., essas novas estruturas sociais põem em causa a relevância social do jornalismo profissional.

Como solução recente, infelizmente, porções da mídia impressa e eletrônica têm feito uma transição a caminho de uma produção de informação destinada a satisfazer nichos de audiência gerados por tendências ideológicas e políticas. Isto é, grupos conservadores consomem mídia conservadora, enquanto seus opositores liberais consomem mídia liberal. Por consequência, em vez do debate público de ideias a tendência é produzir mais polarização social, pois informar-se converte-se, assim, em um exercício de satisfazer, confirmar ou reforçar os próprios prejuízos.

Nessas circunstâncias, as liberdades de imprensa e expressão e o direito de saber, como condições fundamentais para o exercício de um jornalismo livre, resultam 
cada vez mais difíceis de serem exercidos, perante uma estrutura profissional colapsada pelas pressões internas e externas, pela inviabilidade de seus modelos de negócio e suas estruturas anacrônicas/analógicas, e pela sua própria perda de relevância.

Ao mesmo tempo, a mudança organizacional e profissional do jornalismo se apresenta perante nós como uma terra incógnita que precisa de respostas mais criativas, colaborativas, solidárias e eficazes, como corresponde aos valores mais representativos da cultura digital contemporânea e de sua expressão na Web 2.0.

\section{Os planos de ação}

Se aceitarmos que já contamos com informação suficiente perante essas evidências, agora urge-nos passar da reflexão às propostas e os planos de ação.

As organizações dedicadas a apoiar o jornalismo e a capacitar jornalistas, incluindo os centros universitários formais e os de capacitação não formal, não têm necessariamente como objetivo a mudança social, nem como missão a transformação do contexto. Porém, sua função social resulta insubstituível neste momento, pois são as únicas entidades com capacidade para demonstrar que há um futuro relevante para o jornalismo profissional.

Por um lado, a educação formal já não é a maior parte de nossa aprendizagem. As pessoas aprendem de formas diversas e também quando fazem tarefas relacionadas com o mundo do trabalho. Em outras palavras, a aprendizagem constitui um processo contínuo que dura toda a vida, de maneira que os mundos da educação e do trabalho já não permanecem separados (SIEMENS, 2005; VAILL, 1996). Em muitos momentos confluem e, no caso do jornalismo, a aprendizagem do ofício é evidentemente um saber fazer que não pode ser substituído com teorias e lucubrações.

De outro, os corpos docentes de nossas instituições, com valiosas, mas contadas exceções, têm demorado muito para completar - e, em numerosos casos, mesmo em iniciar - sua migração ao mundo digital. Portanto, mesmo se esses indivíduos adquiriram o ofício no mundo analógico, essa experiência resulta cada vez menos pertinente e mais desatualizada para as demandas de uma nova paisagem multimidiática e digital em permanente evolução.

Uma boa porção da mídia, inclusive comunitária, tem iniciado um importante caminho de renovação da prática jornalística ao incorporar as novas TICs digitais ao 
próprio ofício (GIRARD, 2003). Infelizmente, esses valiosos antecedentes não se refletem da mesma maneira no campo da educação formal, em geral, e de jornalistas, em particular.

A produção social de conhecimentos, desde finais dos anos 1990, começou a deslocar seu eixo tradicional da educação formal - como coluna vertebral do sistema de ensino-aprendizagem - para formas de aprendizagem não formal e informal, que, por si sós, constituem uma razão suficiente para que as instituições educativas revisem as prioridades de sua própria estrutura: segundo a UNESCO, o modelo atual de aprendizagem tem se difundido muito além do universo dos educadores e tem se estendido a todos os âmbitos da vida econômica e social; as demandas de educação (básica, primária, secundária, terciária, técnica, não formal e permanente) têm aumentado em todas as sociedades e excedem a oferta atual. Nesse sentido, toda organização educativa precisa hoje alargar sua "dimensão de aprendizagem" (UNESCO, 2005).

Qual o significado, hoje, do chamado alargamento? Durante quase todo o século XX a aprendizagem focou-se na aquisição de habilidades ou na transmissão de informação, no que tem sido chamado de "aprender a respeito de". No final do século passado, algumas teorias da aprendizagem começaram a reconhecer o valor do "aprender a ser", colocando, assim, o aprendizado num contexto situacional vinculado tanto com sistemas e identidades como com a transmissão de conhecimento.

Não obstante, no século XXI já não resulta suficiente essa aproximação. O "aprender a respeito de" e o "aprender a ser" funcionaram bem na relativa estabilidade do século XX; porém, no nosso mundo contemporâneo, em fluxo constante, precisamos assumir uma teoria do "aprender a se tornar" (learning to become): "ali, onde a maioria das teorias da aprendizagem entende 'se tornar' como um estado de transição para chegar a ser algo, gostaríamos de sugerir que o século XXI precisa que pensemos na aprendizagem como uma prática de se tornar uma e outra vez" (THOMAS; BROWN, 2009, p. 1).

E isso está ligado a um diagnóstico da realidade atual segundo o qual: as tecnologias estão "alterando" (re-conectando) nosso cérebro; as ferramentas que usamos definem e dão forma ao nosso pensamento; tanto os indivíduos quanto as organizações aprendem; a crescente atenção à gestão do conhecimento evidencia a necessidade de uma teoria que intente explicar o vínculo entre a aprendizagem individual $\mathrm{e}$ 
organizacional; muitos dos processos analisados pelas teorias da aprendizagem (em especial o processamento cognitivo de informação) podem ser agora assumidos ou apoiados por tecnologia; o saber-como (know-how) e o saber-o que (know-what), são complementados pelo saber-onde (know-where), de tanto se compreender onde achar o conhecimento requerido (SIEMENS, 2005).

A tecnologia baseada na web tem criado espaços educativos em todo o planeta, a tal ponto que qualquer indivíduo com acesso à internet pode aprender qualquer coisa, de qualquer pessoa, a qualquer momento. Isto acontece permanentemente, cada vez que usamos um buscador como o Google, encontramos informação na Wikipédia, lemos os resultados de uma enquete online ou olhamos um vídeo no YouTube (BONK, 2009).

Um modelo chamado "WE-ALL-LEARN" ("todos aprendemos") sublinha dez tendências tecnológicas e de aprendizagem essenciais para mostrar de que maneira as TICs, também chamadas tecnologias cognitivas, têm transformado as oportunidades educacionais para aprendizes de todas as faixas etárias e em todo o planeta:

A Web Searching in the World of e-Books (Buscas Web no mundo dos livros eletrônicos);

A E-Learning and Blended Learning (Aprendizagem em rede e misturada);

A Availability of Open Source and Free Software (Disponibilidade de software livre e de fonte aberta);

A Leveraged Resources and OpenCourseWare (Alavancagem de recursos para projetos destinados a facilitar o acesso online a todo o material pedagógico de cursos: planos, anotações, exercícios, soluções e obras de referência, tal como um projeto do Massachusetts Institute of Technology - MIT);

A Learning Object Repository and Portals (Repositórios e portais de objetos de aprendizagem);

A Learner Participation in Open Information Communities (Participação dos aprendizes em comunidades abertas de informação);

A Electronic Collaboration (Colaboração em redes eletrônicas);

A Alternate Reality Learning (Aprendizagem baseada em realidades alternadas ou virtuais);

A Real-Time Mobility and Portability (Mobilidade e portabilidade em tempo real);

A Networks of Personalized Learning (Redes de aprendizagem personalizada) (BONK, 2009). 
Todavia, todas essas inovações já existentes, e em pleno desenvolvimento e crescimento, não respondem por inteiro à urgente e necessária renovação nas organizações formadoras de jornalistas.

Um jornalismo para o século XXI não deve inovar somente suas práticas, enquanto ofício, mas responder a um contexto cujo problema já não é a falta de informação (de fato, ela circula em excesso), mas o sentido que as pessoas podem lhe dar, para entender um contexto cada vez mais cambiante e complexo, de maneira que as fontes e a segmentação tradicional da informação têm que se renovar forçosamente.

\section{A mudança hiper-exponencial}

Gordon Moore, co-fundador da Intel, afirmou nos anos 1960 que a capacidade dos microprocessadores se duplicaria a cada 18 a 24 meses. Assim nasceu a "Lei de Moore". Naquela época, os circuitos integrados tinham 200 transistores e eram rudimentares e caros. Texas Instruments os vendia aos militares dos Estados Unidos a US\$1.000 dólares cada um. Quando chegou o Y2K - ano 2000 - um chip Pentium III tinha 28 milhões de transistores. Em 2003, Moore afirmou, durante a International Solid-State Circuits Conference, que seu prognóstico cumprir-se-ia durante mais dez anos. "Em certos mercados você pode arrumar, atualmente, cinqüenta milhões de transistores por um dólar", disse Moore. E calculou que, para 2005, a Intel produziria chips com mil milhões de transistores. Em 2008, durante a mesma convenção de circuitos integrados de estado sólido, a Intel introduziu seu processador Itanium Tukwila, com 2.000 milhões de transistores.

As infra-estruturas digitais - compostas de instituições, práticas e protocolos que organizam e introduzem conjuntamente nas sociedades esse poder crescente da tecnologia digital - têm um ritmo de mudança hiper-exponencial, cuja dinâmica fundamental transborda a própria lei de computação de Moore, para ingressar nos domínios da comunicação - o armazenamento e o conteúdo - até constituir um sistema de computação ubíqua (HAGEL III; BROWN; DAVISON, 2009; BROWN, 2006; WEISER; GOLD; BROWN, 1999). A noção de lei apenas representa uma regularidade superável pela acelerada inovação. Porém, é útil para mostrar a complexa trama do paradigma tecnológico da sociedade em rede assim como para descrever o poder da internet: (1) a "lei da fibra" indica que a cada nove meses (o dobro de Moore) duplica-se 
a capacidade de aumentar a largura de banda das fibras ópticas e os amplificadores ópticos que constituem a infra-estrutura básica da comunicação em rede; (2) a "lei do disco" estabelece que a capacidade de armazenamento num suporte físico duplica-se a cada 12 meses; (3) a "lei da comunidade" ou do conteúdo (num contexto em que esse tende a ser produzido com base em colaboração) calcula que, quando se elimina a distância, o número de comunidades virtuais que pode surgir é proporcional a 2 elevado à quantidade de gente com acesso à tecnologia, o que representa uma magnitude descomunal na atualidade (BROWN, 2002).

$\mathrm{O}$ crescimento é chamado de hiper-exponencial porque não se trata de leis independentes, mas interativas. Em decorrência disso, o poder digital equivale a multiplicar as capacidades de computação, comunicação, armazenamento e conteúdo que explicam a dimensão e a profundidade da mudança produzida pela cultura digital e sua capacidade de afetar todos os aspectos de nossas vidas, nosso trabalho e nossa aprendizagem: a capacidade de reduzir os preços enquanto aumenta-se a performance da computação, no que diz respeito ao armazenamento e à largura de banda, nos conduz a uma taxa de adoção da nova "infra-estrutura digital" que é de duas a cinco vezes mais veloz que a de infra-estruturas prévias como as redes elétricas e telefônicas (HAGEL III; BROWN; DAVISON, 2009).

Vivemos num mundo em constante mudança, e por isso as necessidades educacionais do século XXI se defrontam com problemas cada vez mais sérios para serem respondidos pela maioria das práticas educacionais contemporâneas. Se as ditas práticas focam em transferir conhecimento estático (a classe expositiva tradicional é seu melhor exemplo), elas simplesmente não conseguem atingir a velocidade da mudança. Se as práticas procuram se adaptar ou reagir à mudança, podem até dar uma melhorada no resultado, mas do mesmo jeito serão transbordadas por um contexto que precisa atualizar os conteúdos tão rápido quanto vão acontecendo.

Em decorrência disso, observam Thomas e Brown (2009), o que a gente precisa para atingir sucesso em educação é uma teoria que responda a um contexto em fluxo constante, ao mesmo tempo em que mantém suas raízes em uma teoria da aprendizagem. Por isso, compreender os processos de aprendizagem que estão por trás das práticas emergentes de participação em redes digitais poderia fazer com que pudéssemos planejar ambientes de aprendizagem que tirem proveito do poder da participação digital para a educação no século XXI. 


\section{O jornalismo de inovação}

Nesse sentido, o chamado "jornalismo de inovação" (conhecido em inglês como "Injo" -Innovation Journalism) é um jornalismo capaz de agir no novo contexto digital e, ao mesmo tempo, de cobrir a inovação como força social transformadora por excelência. Ele inclui processos e ecossistemas de inovação, oferece a seus públicos uma compreensão de como acontece a inovação e brinda linguagens e narrativas para promover o debate público (USKALI; NORDFORS; SANDRED, 2008).

Para esse jornalismo, o próprio processo de inovação é o conceito central, seja falando de negócios, tecnologia, política etc., ou como componente imbuído numa história. Em termos de reportagem tradicional, trata-se de um jornalismo multidisciplinar que pode ser entendido como uma reportagem horizontal ou como um tratamento dentro da reportagem tradicional. O jornalismo de inovação, então, identifica e informa a respeito de assuntos relacionados com ecossistemas de inovação, tais como novos conceitos, interações entre atores relevantes de um fato, ou cadeias de valor baseadas em inovação; ele pode acolher assuntos como ciência e tendências em tecnologia, propriedade intelectual, finanças, estandardização, processos de produção, comercialização de novas tecnologias, modelos de negócio, política, tendências culturais, sociais e assim por diante.

Isto é, a inovação tem mais a ver com um processo que acontece permanentemente no presente do que com uma previsão de futuro. Nesse sentido, o jornalismo de inovação aprofunda a compreensão do novo contexto e suas consequências, e o faz servindo-se do entorno tecnológico de redes digitais em que se produz a informação no mundo contemporâneo. Por exemplo, durante a Seventh Conference on Innovation Journalism, na Universidade de Stanford, em junho de 2010, Krishna Bharat, o criador de Google News, falou sobre as cinco mudanças que marcarão o futuro do jornalismo: (1) especialização temática e geográfica dos periódicos; (2) uso de redes sociais; (3) novo modelo de remuneração pela informação; (4) anúncios inteligentes; e (5) personalização de conteúdo.

A incidência fundamental ao entendermos o jornalismo como um discurso socialmente construído é que a própria profissão tem que se adaptar às transformações desse discurso e da performance jornalística. Vivemos uma alteração profunda das estruturas narrativas, na qual são evidentes o fluxo de conteúdos através de múltiplos 
suportes midiáticos, a cooperação entre múltiplos mercados midiáticos e o comportamento migratório dos públicos dos meios de comunicação como expressões da convergência (JENKINS, 2006).

Sabemos que as especificidades tecnológicas dos novos meios digitais de comunicação condicionam os discursos e refletem transformações tecnológicas, mercadológicas, culturais e sociais, onde a inteligência coletiva vira uma fonte alternativa de poder midiático, pois a produção coletiva de significados, na cultura da convergência, está começando a mudar o funcionamento das religiões, da educação, do direito, da política, da publicidade e mesmo do setor militar (JENKINS, 2006). Por conseguinte, as escolas de jornalismo precisam de uma estratégia digital para enfrentar o presente, e não o futuro.

\section{A mídia cidadã}

Mas começar a mudar não significa que o processo seja completo. Muito pelo contrário, a exclusão digital entendida, em geral, como o acesso desigual às infraestruturas das TICs no mundo é uma realidade muito grave que afeta a milhões de pessoas no planeta inteiro. Isto é, trata-se de uma fissura multiforme, pois não tem uma, mas diversas exclusões digitais misturadas em função de situações individuais, locais, nacionais e transnacionais. Por exemplo, 2.000 milhões de seres humanos ainda não têm eletricidade; 1.000 milhão de pessoas em uns 800.000 povoados do mundo carecem de toda classe de telecomunicações; existem mais de 771 milhões de pessoas adultas analfabetas, a maioria mulheres e habitantes de áreas rurais; cerca de 100 milhões de crianças ainda não foram escolarizadas (UNESCO, 2005).

Sem eletricidade, nem telecomunicações, nem escolarização completa é impossível construir realidades digitais em termos de jornalismo responsável. Portanto voltando ao García Márquez - o primeiro dever das organizações que formam ou capacitam jornalistas seria prepará-los para uma performance em ambidestria forçada (mas planejada como parte da estratégia digital), devido às contradições tão profundas da realidade, em geral, e do próprio ofício, em particular, quando temos que nos defrontar com condições analógicas em paralelo com todas as novidades e as mudanças digitais. 
E isso implica uma profunda transição do próprio processo de ensinoaprendizagem do jornalismo, sem esquecer a sua própria busca pela ética, qualidade, imparcialidade, precisão e equilíbrio. Como diz o Jean François Fogel (2005), “já sabemos qual é o encontro marcado no futuro do jornalismo: um encontro com a audiência que não tem tempo para esperar aos jornalistas a menos que a voz deles, no oceano da informação, se mantenha como algo distinto e imprescindível".

Mas isto não vai acontecer simplesmente por boa vontade. Ainda faltam profissionais do jornalismo capacitados e centrados nos interesses da cidadania, não só porque, em geral, na América Latina faltam recursos e investimentos em jornalismo investigativo. As universidades também não costumam formar profissionais polifônicos, mediadores, capazes de conceber o jornalismo como ato solidário (TONI, 2005).

A mídia, e particularmente a local, tem uma grande capacidade para visar minorias, outras vozes, outros relatos, outro jornalismo. Além disso, pode virar mídia cidadã quando não só faz isso, mas também vira espaço de comunicação onde as vozes locais encontram um jeito de falar, narrar, propor e debater publicamente (RODRÍGUEZ, 2007). Nesse sentido, a mídia pode ser uma mediadora permanente dos discursos sociais (político, econômico, religioso, educativo, entre outros), visando o aprendizado de conhecimentos, atitudes e práticas pertinentes e importantes para seus destinatários.

Ao mesmo tempo, ao agir como espaço real de comunicação, a mídia cidadã faz empowerment (descentralização e delegação de poderes de decisão, autonomia e participação). Dessa forma, a comunicação deixa de ser apenas um instrumento de persuasão e mobilização para virar espaços dialogais onde a interação de cidadãs e cidadãos faz com que elas e eles se apropriem do futuro enquanto falam, narram, contam, mostram o mundo em suas próprias palavras e imagens.

Não chegou mesmo a hora de mudar o jeito de ensinar e aprender jornalismo? 


\section{Bibliografia}

BONK, Curtis Jay. The world is open: how Web technology is revolutionizing education. San Francisco, Calif: Jossey-Bass, 2009.

BROWN, John Seely. "New Learning Environments for the 21st Century - Exploring the Edge - Fresh approaches to enhancing learning through technology help students bridge the gap between knowledge and knowing”. Change. 38 (5), 2006. p. 18.

The Social Life of Learning: How Can Continuing Education Be Reconfigured in the Future? Continuing Higher Education Review, 66, 2002. p. 50-69.

CASTELLS, Manuel. "Materials for an explanatory theory of the network society", British Journal of Sociology, 51 (1), 2000. p. 5-24.

. La Era de la Información. Economía, Cultura y Sociedad, 3 vols. (1. Sociedad red, 2. El poder de la identidad, 3. El fin del milenio). Madrid: Alianza Editorial, 1997.

CEBERIO, Jesús. Entrevista - Gabriel García Márquez: “«Crónica de una muerte anunciada» es mi mejor novella”. En 24 horas se vendieron en España 35.000 ejemplares. El País, Madrid, 01/05/1981.

COLE, Jeffrey I. et al. The Digital Future Report 2008. Surveying the Digital Future, Year Seven: Seven Years of Exploring the Digital Domain. Los Angeles: USC Annenberg School Center for the Digital Future, 2008.

CORTÉS, Carlos Eduardo. ¿Cuándo comenzamos a hablar de banda ancha comunitaria? Nuevos desafíos en política pública de radiodifusión. In: GUMUCIO-DAGRON, Alfonso, HERRERA-MILLER, Karina (Coord.). Políticas y legislación para la radio Local en América Latina. La Paz: Plural Editores, 2010.

. Viscosidad mediática en la Web 2.0: diez dimensiones múltiples de la brecha digital. In: OCLACC-UTPL. Comunicación, ciudadanía y valores. Re-inventando conceptos y estrategias. Quito: OCLACC, 2008.

Centros Comunitarios Multimediales con fluidez informacional: Guía de herramientas para el desarrollo sostenible en la sociedad de la información. In: CORTÉS, Carlos Eduardo (Ed.).

Fortalecimiento de los Telecentros en Centroamérica. San José de Costa Rica: UNESCO, 2006.

COVEY, Nic. How Teens Use Media: A Nielsen report on the myths and realities of teen media trends. New York: The Nielsen Company, 2009.

FOGEL, Jean François. El futuro ya tiene 10 años. In: CAF / FNPI. ¿Hacia dónde va el periodismo? Responden los maestros. Bogotá: CAF / FNPI, 2005.

GIBS, Jon. The Shifting Media Landscape: Integrated Measurement in a Multi-Screen World. New York: The Nielsen Company, 2009.

HAGEL III, John; BROWN, John Seely; DAVISON, Lang. The Big Shift: Why It Matters. San Francisco: Deloitte Center for the Edge, 2009.

INTERNATIONAL TELECOMMUNICATION UNION. Measuring the Information Society. Ginebra: ITU/UIT, 2010.

JENKINS, Henry. From YouTube to YouNiversity. Chronicle of Higher Education (Washington, DC), 53, n. 24, 2007.

Convergence Culture: Where Old and New Media Collide. Nueva York: New York University Press, 2006. Edição em português: Cultura da convergência. São Paulo: Aleph, 2008.

JENKINS, Henry; THORBURN, David. Rethinking Media Change: The Aesthetics of Transition. Media in transition. Cambridge, Mass.: MIT Press, 2004. 
MORDUCHOWICZ, Roxana (Coord.). Los jóvenes y las pantallas: nuevas formas de sociabilidad. Serie Culturas. Barcelona: Gedisa, 2008.

NIELSEN CONVERGEnCE PANEL / YAHOO! The American Media Multi-Tasker Study. New York: The Nielsen Company, 2010.

ONEPOINTNINE-SYNOVATE / MICROSOFT. Young Adults Revealed: The lives and motivations of 21st century youth. Seattle: Microsoft Advertising, 2008. Disponível em: $<$ http://advertising.microsoft.com/research/young-adults-revealed $>$.

PINTO, Manuel. “O Jornalismo como Campo Social e como Domínio de Formação”, In: Cadernos do Noroeste / Comunicação e Sociedade, Braga: Universidade de Minho, n.1, 1999, p.75-95.

RODRÍGUEZ, Clemencia. "Periodismo y medios ciudadanos". In: V Seminario sobre Búsqueda de la Calidad Periodística, Monterrey: Corporación Andina de Fomento (CAF) y Fundación Nuevo Periodismo Iberoamericano (FNPI), outubto 1-2, 2007.

SIEMENS, George. Connectivism: A Learning Theory for the Digital Age, International Journal of Instructional Technology and Distance Learning, vol. 2 n. 1, jan, 2005. Disponível em: $<$ http://itdl.org/journal/jan_05/article01.htm>

THOMAS, Douglas; BROWN, John Seely. Learning for a World of Constant Change: Homo Sapiens, Homo Faber \& Homo Ludens revisited, Los Angeles: University of Southern California, 2009. (Paper presented at the 7th Glion Colloquium).

TONI, Márcia de. Panorama de la radio en Brasil. In: I Encuentro de conductores y directores de radios informativas de América Latina y el Caribe. Seminário "El Liderazgo ciudadano del periodismo radial ante el reto de la transparencia y la eficiencia en la prestación de servicios públicos". Cartagena de Indias: Fundación Nuevo Periodismo Iberoamericano, 10-12 de março, 2005.

UNESCO. Informe Mundial de la UNESCO - Hacia las sociedades del conocimiento. París: Ediciones UNESCO, 2005.

UNIVERSAL MCCANN. Power to the people - Social Media Tracker Wave 4. London: UM-EMEA, 2009. Disponível em: <universalmccann.bitecp.com/wave4/Wave4.pdf>

UNIVERSITY OF CENTRAL FLORIDA, Welcome to the Information Fluency Strand, UCF Faculty Development Summer Conference, 2005.

USKALI, Turo; NORDFORS, David; SANDRED. The Experience of the Innovation Journalism Fellowship Program 2004-2008 (Stanford Center for Innovations in Learning)", Estocolmo: IAMCR, Jan 2008.

USC Annenberg School Center for the Digital Future, "World Internet Project" (WIP). 2008. Disponível em: <http://www.worldinternetproject.net/>.

VAILL, Peter B. Learning as a way of being: strategies for survival in a world of permanent white water. The Jossey-Bass business \& management series. San Francisco: Jossey-Bass, 1996.

WEISER, Mark; GOLD, Rich; BROWN, John Seely. The origins of ubiquitous computing research at PARC in the late 1980s. IBM Systems Journal. 38 (4), 1999. p. 693.

Este artigo e todo o conteúdo da Estudos em Jornalismo e Mídia estão disponíveis em http://www.periodicos.ufsc.br/index.php/jornalismo/index

Estudos em Jornalismo e Mídia está sob a Licença Creative Commons 
${ }^{\mathrm{i}}$ Conferência de abertura do $2^{\circ}$ Simpósio de Pesquisa Avançada em Jornalismo da Região Sul, promovido pelo POSJOR/UFSC, em 24 e 25 de março de 2011, em Florianópolis, SC.

ii Ver: International Telecommunication Union (2010); Nielsen Convergence Panel / Yahoo! (2010); Covey (2009); Gibs (2009); Universal McCann (2009); Cole et. al. (2008); OnePointNine-Synovate / Microsoft (2008); USC Annenberg School Center for the Digital Future (2008); Morduchowicz (2008).

iii Sem mencionar que, no Brasil, o Supremo Tribunal Federal (STF) decidiu em 2009 que é inconstitucional a exigência do diploma de jornalismo e registro profissional no Ministério do Trabalho como condição para o exercício da profissão de jornalista. 